\title{
WHERE DO TITLES COME FROM?
}

\section{Bal Mukunda Bhandari*}

\section{ABSTRACT}

Students of Master's degree opt for thesis writing, however, soon after they set for proposal writing they could not select a title for them, and they ask their supervisors, professors and seniors for a proper title. Many of them regret for opting thesis writing. This article, based on my experience of supervising and evaluating theses, is an attempt to help the students in general and M.Ed. English students in particular to find title for their thesis. It discusses five sources from which thesis titles come, viz. problem, curiosity, disagreement, various courses and previous works in the related field.

\section{CONTEXT}

In Tribhuvan University, there is a provision, though not mandatory, of thesis writing to complete the master's degree. Students may opt for thesis writing because of three reasons: (i) it helps obtain better division, especially when they are in the margin (ii) it is not necessary to memorize the things from the books so as to answer the questions in the exam (iii) it serves as a foundation for further research, academic or professional. There is a trend among the students in the subjects in which there is no laboratory work that they do not attend the class regularly instead they are somewhere within the country or outside. When the students enter into the process of thesis writing, they find it very difficult, so many of them again go back to the course work. Most of the students spend time not being able to select a title for their research, and whenever they meet their professors, seniors or experts they ask a title for their thesis. This article, therefore, suggests the ways of finding research titles for M.Ed. English students.

\section{INTRODUCTION}

People have different feelings about the term 'research' which comes from old French recerchier and middle French recherché meaning to go about seeking. Some people feel it high-sounding while others feel it laborious. Some people think it is not within the reach of them and are afraid of it while others love it. Research as Merriam Webster's Collegiate Dictionary defines is a careful and diligent search. It is the investigation or experimentation aimed at the discovery and interpretation of facts. It can also be carried out for revision of accepted theories or laws in the light of new facts. A piece of research may be carried out to receive a degree from a university or to develop profession or to solve some practical problems. My concern in this article is academic research which as Kumar (1999:14) mentions undergoes the following steps.

(i) Formulating a research problem

(ii) Conceptualizing a research design

Dr. Bhandari is an Associate Professor in the Central Department of Education, T.U., Kirtipur, Nepal. 
(iii) Constructing an instrument for data collection

(iv) Selecting a sample

(v) Writing a research proposal

(vi) Collecting data

(vii) Processing data

(viii) Writing a research report.

The students who opt for thesis writing for the requirement of a university degree have to go through the above eight steps. Most of the students who are doing their Master's degree get stuck on the first step. They are unable to select an appropriate title for them as "Searching a title for thesis is seldom a simple matter even after you discover a title that attracts your interest, you may well find yourself revisiting your choice, modifying your approach, or changing title altogether after you have begun research" (Gibaldi, 2000: 4). You can use one of the models of research. It may be survey, experiment, ethnography, case study or action research, and you can choose qualitative or quantitative design depending upon the nature of the issue, your knowledge, resources and enthusiasm. Only after a research topic has been chosen can decision be made as to what data would be relevant to its investigation and how such data can best be obtained (Allwright in Johnson and Johnson, 1999). Thesis titles come from various sources; among them five sources are discussed below.

\section{THESIS TITLES COME FROM PROBLEMS}

As a student or a teacher you may have faced many problems and you may have tried to escape from them. Very often you may have become frustrated from your work. Now it's time to realize that problems can be your resources.

Problem 1: An M.Ed. student of mine who was also a teacher once went to test speaking skill of SLC students. He asked questions like, where are you from? (Showing a picture of a bird over a tree) what is this? (Showing a picture of a bird over a tree) where is the bird? He asked pairs of students to talk about their family members and activities like this. Most of the students did not answer his questions. No pair could do the dialogue. The students who were good in the class and those who had done well in the written exam also could not answer his questions.

This might be the problem of your students too. This is the situation that the students are afraid of oral exam and they were nervous. This can be improved by conducting lots of communicative activities in the class. The title of your thesis could be "Developing oral skill through communicative activities."

Problem 2: You are teaching English at secondary level. Your pronunciation is poor. Your students are not satisfied with your teaching because of your pronunciation. You have been trying to improve it. You have been consulting dictionaries and trying to follow the phonemic transcription, yet you could not improve your pronunciation. 
This is a common problem of our teachers. Phonemic transcription may not help you properly. Nowadays learner's dictionaries are available with audio CD. You can listen to the words which come across in the class each day and also practice with the $\mathrm{CD}$, after one month you will find yourself improved. So your thesis title is 'Improving pronunciation through a dictionary CD'. This will be an area of professional development. You can also do this for your students.

Problem 3: Every year you have been teaching different aspects of grammar. You taught prepositions and conjunctions, tense and agreement, voice and narration, conditional sentences and relative clauses and everything of English grammar. The students when they are at sentence level they can answer correctly, but when they write or speak, it seems that they have not studied any grammar.

This is a common problem with most of our students. This is because they were not taught practically. They did not practice at discourse level. They were not exposed to 'real' English. So you can carry out your research on this problem. Thus your title will be 'Teaching grammar at discourse level'.

Problem 4: You have noticed that our teachers' performance is not satisfactory; at the same time you also know that most of the teachers are trained teachers. Teachers are trained but their performance is poor! Why? Now you can carry out your research to find out what is lacking in our teacher training. Where is the problem in policy? in course?, in teacher education?, materials?, in delivery mechanism?, in the trainee? or where? So your thesis title can be 'Gap between training and its output'

\section{THESIS TITLES COME FROM CURIOSITY}

A curious mind comes up with an invention. If you are curious, your curiosity can be a source for your research. How a curiosity can be a source of a thesis title is discussed below.

Curiosity 1: Languages are different. Two languages do not correspond in their system. Yet one language is translated into another. Nepali, for instance, has unknown past but English doesn't. So how have the translators translated Nepali unknown past into English? To quench this curiosity you can take one book (a novel) originally written in Nepali and its translated version in English. At first collect all the sentences that are in unknown past from Nepali text and find out the translated sentences of them and analyze how they have done. Other similar titles are translation of idioms and phrasal verbs, translation of proverbs, translation of professional and vocational terms.

Curiosity 2: In M.Ed. first year grammar course you read that grammar can be taught through text, you became curious to know that how grammar could be taught through texts because you were always taught and you always taught grammar through structures and rules. So you can collect texts from newspapers, magazines or books for the grammar items that you want to teach and teach a particular group of students at least a month. Record the change/progress every 
day and conclude the findings. Other similar titles are teaching grammar through newspaper, teaching grammar through student's language, teaching grammar through learners' dictionaries, etc.

Curiosity 3: When you studied English morphology, you found suffixes and prefixes in English, so is the case with Nepali, but we also find infix in Newari. You are curious to know how infix is used in Newari. So your title can be 'Affixation in Newari and English.' Other similar titles can be pluralization in Nepali and English, tense aspect in Gurung and English, relativization in Maithili and English, concord in Nepali and English. There are so many of such titles.

Curiosity 4: You are curious to know that how much English the students acquire in a year of schooling. In this case you can go to an English medium school and collect data from the students who have passed one year from that school i.e. nursery passed students. Your thesis title will be "Acqisition of English in a year of schooling' or if you want to narrow down the title, it could be 'Acquisition of English vocabulary in a year of schooling'.

Curiosity 5: Some of you have taken IELTS/TOEFL tests, but most of you have heard about them. Those who are going to take these tests prepare themselves attending classes organized for them. But the curiosity is 'what is the level of SLC/+2 graduates in IELTS and/or TOEFL'. So this can be your thesis title.

Curiosity 6: When you studied English phonology, you found that there are 20 vowels and 24 consonants in spoken English, though there are only 5 vowels and 21 consonants in English alphabet. This may arouse curiosity in you. So you can study this system in Nepali or in your mother tongue if it is different from Nepali.

Curiosity 7: All the students in a particular class get same exposure. Same teachers teach them; same question paper is given to them; same way of marking is followed, yet the students obtain different marks. Sometimes among the students of similar talent some get higher marks while others get lower marks. If you are curious to know why this is so, then you are interested to study examination behavior of the students. Such as, how they prepare for the exams; how they organize their answers etc. Thus, your title could be 'Examination Behaviour' or 'Washback Effect' or 'Learner Strategies'.

\section{THESIS TITLES COME FROM DISSATISFACTION/DISAGREEMENT}

During your study you might have come across many things which you could not agree, and you were not satisfied with many explanations. If so, they can be the sources of your thesis titles.

Disagreement 1: Second language teaching methodology suggests that a language should be taught through the same language i.e. there should not be students' mother tongue. But you think that using mother tongue is inevitable, why don't you experiment yourself? So your title is 'Teaching English through English'.

Disagreement 2: During your M.Ed. you were taught that students can learn better/more if they are exposed to real language. But you think that explicit and 
structure teaching will help them learn better/more. So my suggestion is 'don't debate, conduct a research. You teach structured writing, rules, principles, format in one group but supply plenty of examples in another group. Similarly one group you teach grammar other group is exposed to spoken and written real English, one group you teach sound system whereas other group they are simply exposed to native speech by a person in the class or cassettes/CDs or a language teaching program.

Disagreement 3: If you disagree the necessity and importance of lesson planning and you think it is a burden for the teachers, carry out research and see the differences. Your lesson plan should be a 'real' plan of a lesson.

\section{THESIS TITLES COME FROM THE COURSES THAT YOU HAVE STUDIED}

You studied many courses during your study. Thesis titles are hidden in each of the cources. A few of them are discussed below.

(1) In your methodology course you studied that spelling contest increases students' vocabulary repertoire. You have taken it granted but never tested. So carry out an experiment. Your title could be 'Spelling contest for vocabulary enhancement'.

(2) In your literature course you might have studied different approaches to teaching literature but you have probably not used them so far. If you are interested in literature, one of the following approaches can be your area of thesis writing.

(a) New criticism focuses attention on the unity of integration of Literary works. The task of readers is to discourse the reading, focusing formal elements such as ambiguity, irony, simile, metaphor and the effect of connotation and poetic imagery (Cullar, 1997). The world of literary work is self-contained and readers must exercise total objectivity in interpreting the text (Thomson cited in My Van, 2009).

(b) Structuralism is a theory or method which assumes that the elements of a field of study make up a structure in which their interrelationship is more important than any element considered in isolation. An item's role in a structure can be discovered by examining these items which occur alongside it and those which can be substituted for it (Aitchison in Mcarthur, 1992). Structuralism emphasizes total objectivity in examining literary text and denies the role of readers' personal responses in understanding literature (My Van, 2009).

(c) In Stylistis approach students use their linguistic knowledge to make aesthetic judgment and interpretations of the text. This approach analyses the features of literary language to develop students' sensitivity to literature. (My Van, 2009).

(d) EFL teacher training courses offer little guidance on the analytical methods that are essential to interpreting and designing effective classroom activities. Communicative language teaching 'CLT' was criticized for not incorporating content. However, literature can be an excellent vehicle for CLT methods that result in four-skill English 
language development through interaction, collaboration, peer teaching and student independence. Thus your title could be 'Literature in CLT'.

You must have read about varieties of English. There are many Englishs (ie varieties of English) and Nepalese variety of English is one of them. If you are interested in this area you can have many titles. Some of them are:

- $\quad$ Study of stress and intonation in Nepalese English

- $\quad$ Patterns of spoken English in Nepalese variety

- $\quad$ Analysis of linguistic features in Nepalese English

- $\quad$ Figures of speech in Nepalese English.

You did scientific study of the English language. You studied phonological, morphological, syntactic and semantic system of English. You also studied various subsystems under each system. You studied how English words are built. The processes of word formation in English are: affixation, compounding, derivation, blending, shortening, acronym, borrowing, etc. So you can compare a Nepalese language (preferably your mother tongue) with that of English. Thus your title will be "A comparative study of word formation' in Magar/Gurung/Maithili/Limbu and English".

Many children acquire two languages together are their mother tongue and another the language spoken in the community. In this case you can collect data from a few children of 2 years old, and compare acquisition of the two languages (you are suggested to compare one aspect).

In a workshop that was organized for Higher Secondary level English teachers where I distributed an answer copy (which I had made many by means of Xerox) of class twelve to 32 teachers for marking. When I saw the marking, it was surprising. Out of 100, the marks varied from 26 to 52 (Bhandari, 2005). Such a great difference! The same copy was marked differently. This is the reason our students often complain about the marks they get. If this case is interesting to you, you can write your thesis in this area. You may try to find out how the gap could be minimized.

\section{THESIS TITLES COME FROM PREVIOUS WORKS/THESES}

The following are the titles of the theses which were already submitted to the department of English education TU, Kirtipur. There are over 2000 theses in the department library. If you belong to the campuses other than Kirtipur, you can also find some theses there. The previous theses can help you find out a title for your thesis. Let us discuss how each of the following theses generate titles for further research.

1. Analysis of vocabulary used in the English textbooks for grade one. This researcher has analyzed the vocabulary items used in the English textbook of grade one. On the basis of this thesis you can generate the following titles and many others.

- $\quad$ Syntactic analysis of our English book grade 5/6/7/8(choose one) 
- $\quad$ Correlation between curriculum and textbook: A case study of class 9 English text book(you can choose any other book)

- Form function reciprocity in Lotus English Reader for grade $5 / 6 / 7 / 8$ (choose one)

- Comparative study of English textbooks: A case of Lotus and Symphony of class 4/5/6(choose one)

2. Let us consider the second thesis entitled' Effectiveness of teaching vocabulary through games'. From this thesis you can obtain many titles.

- Developing aural-oral skill through games

- Developing communicative skills through games

- Developing aural-oral skills through one act plays

- Developing writing through parallel texts

3. The third thesis in our discussion is 'Noun phrase structure in Nepali and English'. This thesis gives clues to generate many titles of similar types. You can compare noun phrase structure of other Nepalese languages with that of English. You can also compare verb phrase, adjective phrase or adverb phrase. Similarly pluralization, passivization, negation, relativization, etc can be the areas of study.

The titles below can also help you find your thesis title.

- $\quad$ A comparative study of word formation in English and Maithili'

- A comparative Study of English of NTV and BBC

- $\quad$ Learning strategies in second language acquisition.

- Teaching of Speaking at the Secondary Level: An Analysis of Classroom Activities

- $\quad$ Effectiveness of Strip Story in Teaching Reading Comprehension

- $\quad$ An Analysis of Multiple Translation of 'Paral Ko Aago'.

- $\quad$ Transfer of Teacher Training in Teaching Speaking Skills.

- $\quad$ Effectiveness of Self Correction and Teacher Correction.

\section{CONCLUSION}

In this paper I have discussed five sources from which titles for theses come. All these five sources are interconnected. If you pull the thread of one, you will pull all of them. I have seen students who sit and meditate for a thesis title. My suggestion to them is to follow what I have put forward in this article. I think it is the will that helps you find titles for your research.

\section{WORKS CITED}

American Psychological Association (2006). Publication Manual of the American Psychological Association (sixth edition). American Psychological Association, Washington, DC.

Bhandari, B.M. (2005). Testing: A Question of Reliability. In Journal of NELTA. Vol. 10: Nepal English Language teachers' Association, Kathmandu. 
Culler, J. (1997). Literary Theory. Oxford University Press, Oxford.

Cohen, L., Manion, L. and Morrison, K. (2007). Research Methods in Education. Routledge, London.

Gibaldi, J. (2001). MLA Handbook for Writers of Research Papers .Affiliated East-West Press Pvt. Ltd., New Delhi.

Johnson, K. and Johnson, H. (1994). Encyclopedia Dictionary of Applied linguistics: Blackwell Publishers, Oxford.

Kumar, R. (1999). Research Methodology. Sage Publication, London.

McArthur, T. (1992). Oxford Companion to the English Language. University Press, Oxford.

My Van, T.T. (2009). The Relevance of Literary Analysis to Teaching Literature in the EFL Classroom. In English Language Teaching Forum Vol. 47, No. 3.

Nunan, D. (1993). Research Methods in language Learning. Cambridge University Press, Cambridge.

Paltridge, B. and Starfield, S. (2007). Thesis and Dissertation writing in a second language. Routledge, London. 